\title{
NGHIÊN CÚ̉U QUY TRÌNH PHÁT HIỆN BIẾN ĐộNG ĐẤT ĐAI PHỤC VỤ CHO CÔNG TÁC QUẢN LÝ ĐẤT ĐAI BẰNG CÔNG NGHẸ BAY CHỤP ẢNH TỬ THIẾT BỊ BAY KHÔNG NGƯỜI LÁI (UAV)
}

\author{
LÊ TH! KIM DUNG \\ Trường Đại học Tài nguyên và Môi trường Hà Nội
}

\section{Tóm tắt:}

Việt Nam là một quốc gia có nguồn tài nguyên đất đai hạn chế, bên cạnh đó do áp lực gia tăng dân số, quá trình công nghiệp hóa đô thị hóa đòi hỏi công tác quản lý nguồn tài nguyên đất đai hiệu quả đang trở nên cấp thiết. Để làm được điều đó cần cập nhật liên tục những thông tin về quỹ đất và tình trạng sử dụng chúng. Phương pháp truyền thống để đánh giá sự biến động về đất đai là phương pháp đo đạc ngoài thực địa nhưng phương pháp này tốn nhiều công sức và thời gian. Xu hướng của thế giới hiện nay là dựa trên kết quả xử lý ảnh hàng không hoặc ảnh vệ tinh để thực hiện giám sát tình trạng bề mặt trái đất nhằm đánh giá sự biến động đất đai. Nội dung bài báo giới thiệu quy trình phát hiện biến động đất đai phục vụ cho công tác quản lý đất đai bằng công nghệ bay chụp ảnh từ thiết bị bay không người lái (UAV).

\section{Mở đầu}

Đất đai là nguồn tài nguyên vô giá, là thành phần quan trọng nhất của môi trường sống, là địa bàn phân bố các khu dân cư, các cơ sở sản xuất, các công trình văn hóaxã hội, đồng thời đất đai cũng được xem như một loại hàng hóa đặc thù. Tuy nhiên đất đai có những tính chất đặc trưng mà các loại tư liệu sản xuất khác không có được như: hạn chế về diện tích, có vị trí cố định trong không gian, không thể di chuyển được theo ý muốn của con người. Chính vì lẽ đó, sử dụng đất đai hợp lý, phát hiện và theo dõi những biến động của chúng để quản lý đang trở nên cấp thiết. Hiện nay, có nhiều cách đánh giá biến động đất đai, tuy nhiên sử dụng ảnh thu được bằng công nghệ bay chụp ảnh không người lái (UAV) để giám sát đang là một trong những xu hướng của thế giới. Vì vậy, nội dung bài báo này tập trung vào nghiên cứu quy trình bay chụp và phát hiện sự thay đổi, biến động của đất đai bằng công nghệ bay chụp ảnh từ thiết bị bay không người lái (UAV).

\section{Quy trình phát hiện biến động đất} đai và công nghệ UAV

Một trong những nội dung quan trọng trong công tác quản lý nhà nước về đất đai là công tác theo dõi và chỉnh lý sự biến động nhằm mục đích quản lý quỹ đất đai có hiệu quả, nắm được tình hình sử dụng đất và những biến đổi của quá trình đó. Để thực hiện được điều đó đòi hỏi cập nhật thường xuyên những thông tin quan trọng về sử dụng đất thông qua việc đăng ký, chỉnh lý, cập nhật biến động đất đai trên hồ sơ địa chính, hoàn thiện cơ sở dữ liệu đất đai. Hiện nay, có nhiều phương pháp khác nhau trong việc đánh giá, phát hiện sự biến động về tình trạng đất đai. Theo phương pháp truyền thống, thông qua thống kê và kiểm kê đất đai, nhà quản lý xác định được sự thay đổi về diện tích và mục đích sử dụng trên cơ sở

Ngày nhận bài: 18/7/2017, ngày chuyển phản biện: 21/7/2017, ngày chấp nhận phản biện: 18/8/2017, ngày chấp nhận đăng: 07/9/2017 
đo đạc thực địa. Phương pháp này có độ chính xác cao, tuy nhiên việc đo đạc được thực hiện ở ngoài trời nên phụ thuộc lớn vào thời tiết, phạm vi đo đạc hẹp và chi phí đo đạc cao.

Phương pháp đo vẽ bằng ảnh viễn thám có độ chính xác tương đối cao trong điều kiện thời tiết thuận lợi và khu vực khảo sát có địa hình chênh cao không nhiều. Việc chụp ảnh và xử lý ảnh có thể thực hiện trên phạm vi rộng, tiết kiệm về thời gian và kinh phí, đồng thời, nâng cao độ chính xác của thông tin về đất đai. Trên thế giới, nhiều nơi đã sử dụng máy bay không người lái để thực hiện bay chụp ảnh, sử dụng ảnh chụp được để xử lý và giám sát trạng thái đối tượng trên bề mặt Trái đất. Sự phát triển của việc thu nhận hình ảnh trên máy bay không người lái được bắt đầu từ năm 1858 khi Gaspard Felix Tournashon sử dụng khinh khí cầu để thực hiện việc chụp ảnh từ trên không ở Paris. Sau đó, để thực hiện việc chụp ảnh trên không, những ý tưởng về máy bay không người lái đã phát triển một cách nhanh chóng, điểm nhấn của quá trình này là việc dược sỹ người Đức Julius Neubronner đã được cấp bằng sáng chế khi sử dụng chim bồ câu để chụp ảnh phong cảnh từ trên cao.

Cấu tạo hệ thống chụp ảnh hàng không kỹ thuật số bằng máy bay không người lái (UAV) có thể được chia thành 4 phần chính như sau: hệ thống máy bay, máy ảnh kỹ thuật số, trạm điều kiển mặt đất, trạm xử lý ảnh.

Để đánh giá sự biến động sử dụng đất, việc thực hiện bay chụp ảnh bằng công nghệ bay không người lái thường được thực hiện ở 2 thời điểm khác nhau. Việc khảo sát được thực hiện ở 3 giai đoạn: giai đoạn chuẩn bị, ngoại nghiệp và nội nghiệp.

Giai đoạn chuẩn bị bao gồm các hoạt động về hoạch định vị trí, xác định phạm vi cần bay chụp, kiểm tra vùng cấm bay và thời tiết có thuận lợi cho công việc bay chụp hay không. Sau khi kiểm tra tất cả các điều kiện đảm bảo cho việc bay chụp, sau đó tiếp đến là thiết kế tuyến bay bằng phần mềm chuyên dụng và tiến hành bay chụp ảnh.

Số liệu thu được từ bay chụp sẽ được xử lý bằng phần mềm xử lý UAV chuyên dụng (Agisoft Photoscan) bao gồm ảnh số và tọa độ các điểm khống chế ảnh. Sản phẩm thu được sau khi xử lý ảnh là mô hình đám mây điểm (Point Cloud), mô hình số bề mặt (DSM), mô hình số độ cao (DEM) và ảnh trực giao (Orthomosaic).

\section{Khu vực thử nghiệm}

Khu vực thử nghiệm thuộc huyện Ba Vì Thành phố Hà Nội. Tiến hành bay chụp ảnh UAV tại hai thời điểm tháng 4/2014 và tháng 12/2015. Độ phân giải mặt đất hai lần bay chụp là $3 \mathrm{~cm}$; độ cao bay chụp $160 \mathrm{~m}$; số lượng ảnh 312 ảnh; diện tích khu bay chụp $1,02 \mathrm{~km}^{2}$. Đồ hình bay chụp theo hình vuông để đảm bảo thu được ảnh trực giao với chất lượng tốt nhất, ranh giới các thửa đất và nhà cửa sẽ được hiển thị tốt nhất trên ảnh.

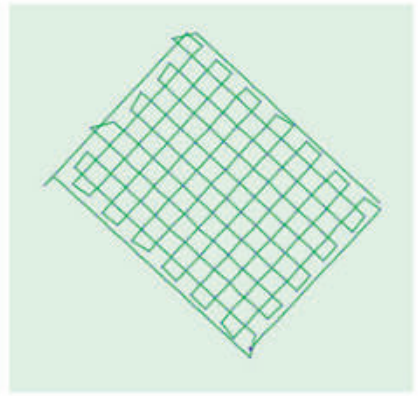

Hình 1: Sơ đồ tuyến bay khu vực thử nghiệm

Sau khi bay chụp, trên khu đo sử dụng 05 điểm KCA đo bằng phương pháp RTK để tăng dày và bình sai khối ảnh. (Xem hình 2)

Sản phẩm bình đồ ảnh trực giao có độ chính xác $5 \mathrm{~cm}$ về mặt bằng ở cả hai thời điểm, đủ điều kiện để tiến hành đánh giá sự biến động về sử dụng đất trên khu vực thử nghiệm. (Xem hình 3) 


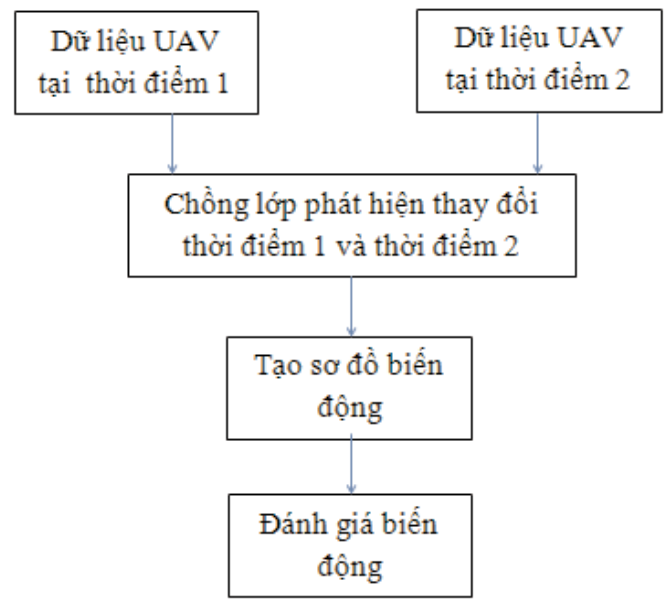

Hình 3: Quy trình phát hiện biển động đẩt đai sau khi thực hiện xử lý ảnh chụp bằng công nghệ bay chụp ảnh từ thiết bị bay không người lái (UAV).

Kết quả thực hiện xử lý ảnh qua 2 thời điểm khác nhau được thể hiện ở những hình ảnh sau: (Xem hình 4, 5)

Việc phát hiện thay đổi tại khu vực thử nghiệm (Thôn Yên Bồ) tại hai thời điểm được phát hiện sơ bộ bằng phần mềm viễn thám ENVI để phát hiện các khu vực có biến động. Tuy nhiên, để chính xác hóa chúng ta phải sử dụng các phần mềm GIS khác để số hóa lại các khu vực biến động để có ranh giới khu vực biến động rõ nét. Tác giả sử dụng phần mềm ArcGIS 10.1 để số hóa lại ranh giới các khu vực có biến đổi.
Qua quá trình phát hiện thay đổi và số hóa chúng ta thấy chỉ sau hơn một năm tại khu vực thử nghiệm đã có 32 sự biến động đáng kể trong đó có 30 ngôi nhà được xây mới diện tích khoảng $2.780 \mathrm{~m}^{2}, 01$ ngôi mộ xuất hiện tại khu đất nông nghiệp (ruộng), 01 khu ao được mở rộng $1.814 \mathrm{~m}^{2}$ (Xem hinh 6)

Qua quá trình phân tích và xử lý, giải đoán bổ sung các thông tin trên ảnh chúng ta có thể thành lập được bản đồ biến động sử dụng đất như hình dưới. (Xem hình 7)

\section{Kết luận và kiến nghị}

Công nghệ bay chụp, thu thập dữ liệu từ thiết bị bay không người lái (UAV) ngày càng phát triển và được ứng dụng trong rất nhiều ngành nghề khác nhau. Trong những năm gần đây công nghệ UAV đã có những bước tiến lớn trong lĩnh vực thành lập bản đồ, mô hình 3D độ chính xác cao. Đặc biệt khi công nghệ bay chụp UAV kết hợp với công nghệ xác định tâm ảnh chính xác RTK sẽ giảm bớt chi phí công tác ngoại nghiệp rất nhiều, trong khi đó vẫn giữ được độ chính xác thành lập bản đồ cần thiết.

Dựa vào nghiên cứu trên, một lần nữa khẳng định công nghệ UAV có đủ độ chính xác, độ tin cậy, và tính ứng dụng cao trong công tác quản lý đất đai mà đặc biệt trong việc phát hiện biến động đất đai phục vụ cho
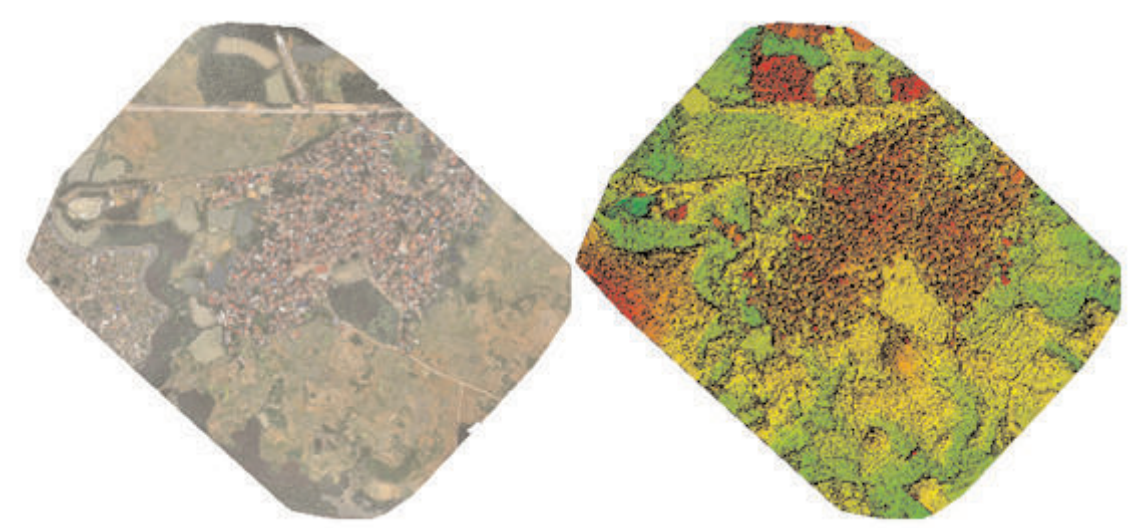

Hình 2: Sản phẩm ảnh trực giao và mô hình số bề mặt khu thử nghiệm 


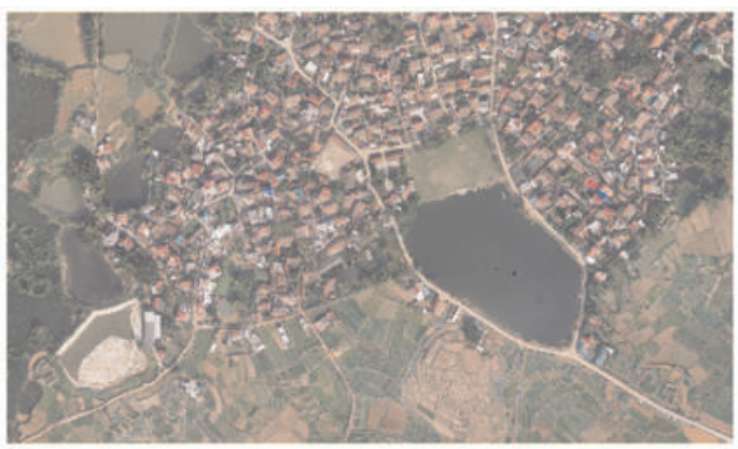

Hình 4: Khu vực thử nghiệm tháng 4/2014

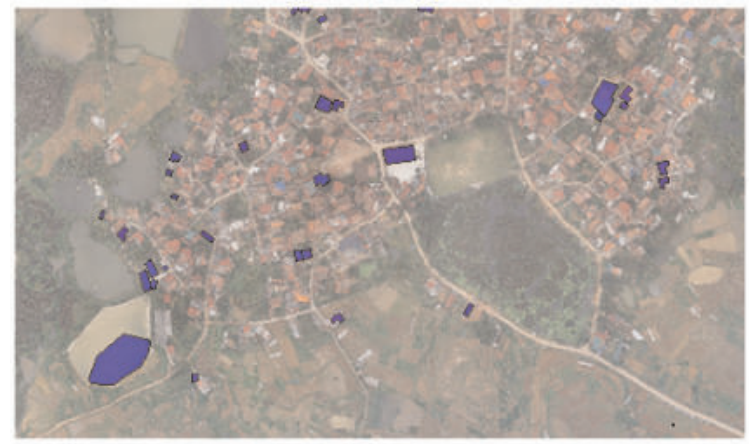

Hình 6: Khu vực biến động trên khu vực thử nghiệm

công việc đánh giá nhằm mục đích thống kê, kiểm kê và công tác quy hoạch, .v.v... Công nghệ này sẽ giúp các nhà quản lý sẽ có cái nhìn chính xác hơn, nhanh hơn, tổng quan hơn về khu vực mình nghiên cứu. Từ đó nhanh chóng đưa ra được các quyết định và giải pháp kịp thời giúp quy hoạch phát triển kinh tế-xã hội và quản lý đất đai một cách hợp lý và hiệu quả nhất. $O$

\section{Tài liệu tham khảo}

[1]. Nguyễn Mạnh Hiển. Xây dựng chiến lược phát triển ngành quản lý đất đai theo định hướng hiện đại hóa, kinh tế hóa và phục vụ mục tiều phát triển kinh tế - xã hội bền vững $\mathrm{http}: / /$ hunre.edu.vn

[2]. Peter Van Blyenburgh, Harmonision UAS Regulations and Standards, GIM International, UAS edition, vol 30 (2016), pp. 6-8.

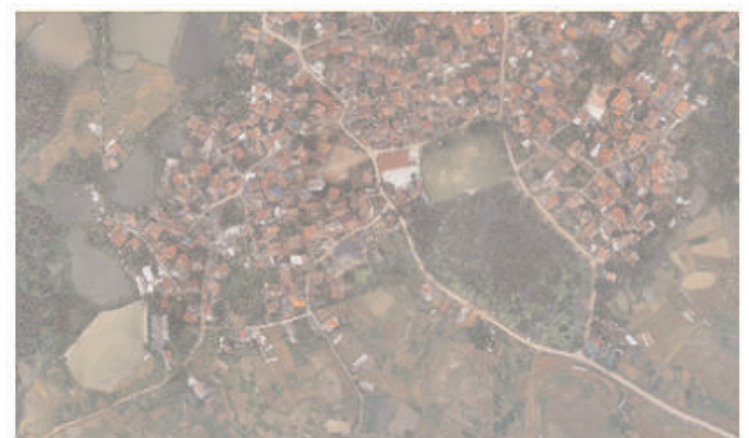

Hình 5: Khu vực thử nghiệm tháng 12/2015

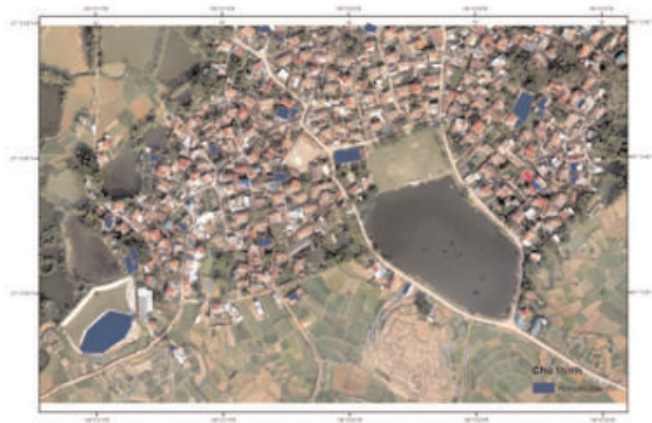

Hình 7: Bản đồ khu vực biến đổi từ 4/2014 đến 12/2015

[3]. Antero Kukko, Anttoni Jaakkola, Juha Hyypa, Airborne laser Scanning using UASs, GIM International, UAS edition, vol 30 (2016), pp. 11-13.

[4]. Tommaselli, A. M. G. and Torres, F. M.: A LIGHT-WEIGHT LASER SCANNER FOR UAV APPLICATIONS, Int. Arch. Photogramm. Remote Sens. Spatial Inf. Sci., XLI-B1, pp.711-715.

[5]. Trang web UAV Geoscan geoscan.aero.

[6]. Trang web UAV Ebee sensefly.com.

[7]. Trang web UAV Trimble UX5 trimble.com/uas. $O$

(Xem tiếp trang 39) 